\title{
ESTRESSE HIIDRICO INDUZIDO POR MANITOL EM SEMENTES DE SOJA DE DIFERENTES TAMANHOS ${ }^{1}$
}

\author{
PAULO ROBERTO COSTA², CECICASTILHO CUSTÓDIO², NELSONBARBOSAMACHADO NETO³, \\ OSWALDO MASSUO MARUBAYASH ${ }^{3}$
}

\begin{abstract}
RESUMO - A primeira etapa na seqüência de eventos da germinação é a embebição. A limitação de água pode diminuir a velocidade de germinação ou até impedi-la. Em condições de deficiência hídrica sementes de diferentes tamanhos podem apresentar comportamentos distintos. O objetivo deste trabalho foi avaliar os efeitos da deficiência hídrica induzida por manitol na qualidade fisiológica de sementes de soja dos cultivares 'IAC-18' e 'IAC-22', classificadas em peneiras nos tamanhos 12 e 13, e, 12, 13 e 14, respectivamente. As sementes foram semeadas em substrato de papel umedecido com soluções de manitol de diferentes concentrações $\left(0 ; 44,58 ; 89,17 ; 133,75 \mathrm{~g} \mathrm{~L}^{-1}\right.$ de água destilada) produzindo os potenciais hídricos de $0,-0,6,-1,2$ e $-1,8 \mathrm{MPa}$, respectivamente. Os tratamentos foram avaliados por meio dos seguintes testes: germinação, primeira contagem de germinação, classificação do vigor das plântulas, comprimento de hipocótilo e raiz e massa seca da parte aérea e raiz. O experimento foi conduzido no delineamento inteiramente casualizado com os tratamentos dispostos em arranjo fatorial 2x4 e 3x4 (tamanho de semente $\mathrm{x}$ concentração de manitol), para cada cultivar. Os resultados indicaram que, para o cultivar 'IAC-18', os potenciais calculados de $-0,52 \mathrm{e}$ $-0,49 \mathrm{MPa}$ permitiram a máxima germinação, respectivamente para as sementes classificadas nas peneiras 12 e 13. Para o cultivar 'IAC-22', nos potenciais calculados de -0,514, -0,51 e -0,46MPa foram obtidas as máximas germinações para as sementes classificadas nas peneiras 12, 13 e 14, respectivamente. Até o potencial de $-1,27 \mathrm{MPa}$ e $-1,04 \mathrm{MPa}$, respectivamente, para os cultivares 'IAC-18' e 'IAC-22', as sementes maiores apresentaram maior germinação. A germinação foi menos afetada que as avaliações de desenvolvimento das plântulas, nos diferentes níveis de potencial, pois estas características foram decrescentes com a diminuição dos potenciais hídricos.
\end{abstract}

Termos para indexação: Glycine max, deficiência hídrica, peneiras, classificação.

\section{WATER DEFICIT INDUCED BY MANNITOL ON SOYBEAN SEED CLASSIFIED IN DIFFERENT SIZES}

\begin{abstract}
The first event in the germination sequence is imbibition. Water uptake limitation has an effect on germination velocity, decreasing or stopping this process. In water stress conditions seeds with different sizes may present different behaviour. The purpose of this study was to evaluate the effects of hydric stress induced by mannitol on the physiological seed quality of soybean cultivar 'IAC-18' classified by size in the 12 and 13 mesh and cultivar 'IAC-22' classified in the 12,13 and 14 mesh. Seeds were sown on paper soaked in mannitol solutions at different concentrations $\left(0 ; 44.58 ; 89.17 ; 133.75 \mathrm{~g} \mathrm{~L}^{-1}\right.$ distilled water $)$ which produced the water potentials of $0,-0.6,-1.2$ and $-1.8 \mathrm{MPa}$. Treatments were evaluated according the following characteristics: germination, first germination counting, seedling vigour classification, hypocotil and root length and shoot and root dry biomass. The experiment was conducted as a completely randomized design with the treatments in a factorial scheme of $2 \times 4$ and $3 \times 4$ (seed size $\mathrm{x}$ mannitol concentration) for each cultivar, respectively. Results showed that calculated water potential at -0.52 and $-0.49 \mathrm{MPa}$
\end{abstract}

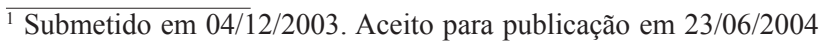

${ }^{2}$ Eng $^{\circ}$ Agr $^{\circ}$, Aluno do Mestrado em Agronomia, Produção Vegetal da UNOESTE, Rod. Raposo Tavares Km 572, 19067175, Presidente Prudente - SP.
} ${ }^{3}$ Eng $^{\circ}$ Agr $^{\circ}$, Dr., Profs. do Departamento de Biologia Vegetal e Fitossanidade,
UNOESTE, Rod. Raposo Tavares Km 572, 19067175, Presidente Prudente
- SP; e-mail: ceci@agro.unoeste.br 
promoted maximum germination for the smallest and largest seeds, respectively. For 'IAC-22' cultivar the calculated water potential of $-0.514,-0.51$ and $-0.46 \mathrm{MPa}$ induced maximum germination for the seeds of 12,13 and 14 mesh, respectively. Up to the water potential of -1.27 and $-1.04 \mathrm{MPa}$ the largest seeds produced the highest germination percentage for 'IAC-18' and 'IAC22' cultivars, respectively. Germination was less affected than the evaluations of seedling development at the different levels of water potential, and these characteristics decreased with the increase in water stress.

Index terms: Glycine max, water stress, mesh, seed classification.

\section{INTRODUÇÃO}

A primeira etapa na seqüência de eventos da germinação é a embebição, um tipo de difusão que ocorre quando as sementes absorvem água. A limitação de água pode diminuir a velocidade da germinação ou até impedi-la. Em trabalhos relacionados com embebição, considerando-se diferentes tamanhos de sementes, têm sido constatado que as sementes de menor tamanho atingem teores de água superiores aos observados para sementes de maior tamanho (Calero et al., 1981; Souza, 1996 e Beckert et al., 2000); esse fato está relacionado à maior área de contato por unidade de massa, nas sementes menores.

A interferência do tamanho da semente na germinação, nem sempre é constatada. Cazetta et al. (1995), utilizando sementes de feijoeiro, verificaram que o tamanho das sementes apresentou pouco efeito sobre a germinação. Segundo Aguiar et al. (2001), não ocorreram diferenças significativas na germinação, em relação ao tamanho das sementes de girassol do cv. Catissol. No entanto, o tamanho das sementes de feijão influenciou direta e significativamente a biomassa seca das plântulas (Cazetta et al., 1995). Em sementes de Acacia senegal (L.) Willd, as plântulas oriundas de sementes maiores apresentaram quase o dobro da biomassa fresca em comparação com aquelas oriundas de sementes menores (Ferreira \& Torres, 2000).

Quando se avalia a produtividade, o tamanho da semente tem demonstrado pouca interferência. Em soja o tamanho não afetou a população inicial estabelecida 30 dias após a semeadura, altura e número de vagens das plantas, produtividade da cultura, tamanho e massa da semente colhida (Lima \& Carmona, 1999). Resultados semelhantes foram obtidos com milho cultivar AL-34, em que a forma e o tamanho das sementes não afetaram o desenvolvimento e a produtividade da cultura (Martinelli-Seneme et al., 2001). Em amendoim, cv. Tatu, na classe de sementes fiscalizadas, verificou-se que a utilização de sementes pequenas (peneira 20), pode alterar a freqüência do tamanho das sementes produzidas (aumento da proporção de sementes de menor tamanho na população) sem que o desempenho produtivo do cultivar seja afetado (Godoy et al., 1996).

A disponibilidade hídrica do substrato pode afetar o

das sementes. Potenciais hídricos do substrato de $-0,4$ e $-0,6 \mathrm{MPa}$ causaram sensível redução na porcentagem de germinação, nas plântulas normais obtidas na primeira contagem do teste de germinação, na velocidade de germinação, no comprimento do hipocótilo e da radícula e na massa seca das plântulas, bem como aumento na porcentagem de plântulas anormais em sementes de feijão cv. IAC-Carioca (Braga et al., 1999). Sementes de soja cv. IAC 15 sofreram redução na emissão da raiz primária e da porcentagem de germinação, em potenciais hídricos do substrato de $-0,20$ e 0,40MPa (Rosseto et al., 1997). O desempenho de sementes de soja sob estresse hídrico ( 0 a - $0,8 \mathrm{MPa})$ está na dependência do potencial fisiológico inicial e o vigor é mais afetado que a germinação para um mesmo nível de potencial hídrico (Braccini et al., 1998). Sob deficiência hídrica o maior tamanho das sementes (Piana, 1980; Martinelli-Seneme et al., 2000) e menor vigor (Sá, 1987; Piana \& Silva, 1998) tem sido associado com menor desempenho.

Este trabalho teve por objetivo avaliar os efeitos causados pela deficiência hídrica induzida por manitol na qualidade fisiológica das sementes de soja dos cultivares 'IAC-18' e 'IAC-22', classificadas em diferentes tamanhos.

\section{MATERIAL E MÉTODOS}

O experimento foi realizado durante o período de setembro a novembro de 2002 no Laboratório de Análise de Sementes da Universidade do Oeste Paulista (UNOESTE), localizado em Presidente Prudente - SP.

Foram utilizadas sementes de soja do cultivar 'IAC-18', classificadas em peneiras 12 e 13, e da 'IAC-22', classificadas nas peneiras 12, 13 e 14, obtidas junto ao Núcleo de Produção de Sementes do Departamento de Sementes, Mudas e Matrizes de Paraguaçu Paulista - SP. As sementes foram submetidas ao teste de germinação em diferentes potenciais hídricos $(0,-$ 
0,6, -1,2 e -1,8MPa) induzidos por manitol, nas respectivas concentrações de $0 ; 44,58 ; 89,17$ e $133,75 \mathrm{~g} \mathrm{~L}^{-1}$ de água destilada, usando-se a fórmula de Van't Hoff citada por Braga et al. (1999).

A determinação do grau de umidade foi feita em base úmida, sendo monitorada por meio do método de estufa a $105 \pm 3^{\circ} \mathrm{C}$ por 24 horas, utilizando-se duas sub-amostras por lote e a massa de 1000 sementes foi determinada utilizandose 8 sub-amostras de 100 sementes por lote, multiplicando a média por 10 (Brasil, 1992).

O teste de germinação foi conduzido com quatro subamostras de 50 sementes por tratamento. As sementes foram dispostas entre três folhas de papel-toalha, umedecidas na proporção de 2,25 vezes a massa do papel seco com as soluções de manitol, confeccionados rolos e estes colocadas em germinador do tipo Mangelsdorf regulado a $25^{\circ} \mathrm{C}$. A porcentagem de plântulas normais foi avaliada aos 5 e 8 dias após a semeadura (Brasil, 1992). As plântulas normais foram separadas, para o teste de classificação do vigor das plântulas, em fracas ou fortes (Nakagawa, 1999), e na primeira contagem do teste de germinação foram consideradas as plântulas normais obtidas aos 5 dias após a semeadura.

A avaliação do desenvolvimento das plântulas foi conduzida usando quatro sub-amostras de 10 sementes por tratamento, colocadas em germinador do tipo Mangelsdorf regulado a $25^{\circ} \mathrm{C}$. As sementes foram colocadas em papel toalha, espaçadas regularmente, em uma linha no primeiro terço do papel-toalha. O desenvolvimento normal da plântula foi quantificado ao quinto dia, medindo o comprimento $(\mathrm{em} \mathrm{cm})$ do hipocótilo e da raiz, além da massa seca (em g) da parte aérea sem os cotilédones e das raízes (Nakagawa, 1999).

O delineamento experimental foi o inteiramente casualizado com quatro repetições, com o arranjo dos tratamentos no esquema fatorial $2 \times 4$ (tamanho da semente $\mathrm{x}$ concentração de manitol) para o cultivar 'IAC-18' e 3x4 para o cultivar 'IAC-22'. Os resultados de porcentagem de germinação, classificação do vigor das plântulas e primeira contagem de germinação foram transformados em arc seno $(\mathrm{X} / 100)^{0,5}$; pois originalmente seguiam distribuição binomial. O comprimento do hipocótilo e da raiz e a massa seca da parte aérea e da raiz não foram transformados. Os dados foram analisados estatisticamente com a ajuda do software SANEST (Zonta et al., 1994), usando o teste de Hartley para verificação da homocedasticidade, o teste $\mathrm{F}$ para análise de variância (Nogueira, 1991), o teste Tukey para a comparação de médias entre os tamanhos das sementes e análise de regressão polinomial para as concentrações de manitol, em nível de 5\% de probabilidade. Os resultados de determinação da massa de 1000 sementes e do grau de umidade não foram analisados estatisticamente pois seguiu-se o número de repetições e os níveis de tolerância indicados em BRASIL (1992) e constituíram informações para caracterização inicial dos lotes, não sendo necessários para comparação de tratamentos.

\section{RESULTADOS E DISCUSSÃO}

Os resultados da avaliação da qualidade inicial das sementes estão apresentados na Tabela 1. O grau de umidade das sementes encontrava-se uniforme, variando de 8,3 a 8,9\%. Os resultados dos testes de germinação, classificação do vigor das plântulas, primeira contagem da germinação, comprimento de hipocótilo e raiz, massa seca de parte aérea e raiz e lixiviação de potássio não indicaram diferenças significativas para as sementes classificadas em diferentes tamanhos dos dois cultivares avaliados.

A germinação das sementes de soja, cultivar 'IAC-18' (Figura 1), aumentou com o decréscimo do potencial hídrico de zero para -0,49 e -0,52MPa, respectivamente para as peneiras 13 e 12 . Após estes níveis, a germinação diminuiu, chegando a valores próximos a zero no tratamento $-1,8 \mathrm{MPa}$.

Não houve diferença, na porcentagem de germinação, entre sementes de diferentes tamanhos, no cultivar 'IAC-18', para os tratamentos 0, -0,6 e-1,2MPa. Entretanto, as sementes maiores apresentaram valores mais elevados de germinação para estes tratamentos. Os resultados de germinação obtidos nos diferentes potenciais hídricos nos dois tamanhos de sementes permitiu o ajuste de equações quadráticas (Figura 1), sendo possível o estabelecimento do potencial hídrico de $-0,49 \mathrm{MPa}$ e de $-0,52 \mathrm{MPa}$ como pontos de máxima, respectivamente para as sementes classificadas nas peneiras 13 e 12. Rosseto et al. (1997) determinaram que sementes de soja submetidas aos potenciais de $-0,2$ e $-0,4 \mathrm{MPa}$ apresentaram redução na emissão de raiz primária e na porcentagem de germinação. Em solo, Peske \& Delouche (1985), trabalhando com sementes de soja, demonstraram que as condições mais favoráveis de umidade para emergência das plântulas, em solo franco-argiloso-siltoso, foi de 13 a $16 \%(-0,2$ a $-0,7 \mathrm{MPa})$ e de 8,5 a $12 \%(-0,03$ a $-0,14 \mathrm{MPa})$, para solo franco-arenoso. A germinação pode ser maior em condição de restrição hídrica, em função da melhor disponibilidade de oxigênio e por redução dos riscos de danos por rápida embebição.

Do mesmo modo, calculou-se que, no potencial de 
TABELA 1. Valores médios obtidos nas determinações preliminares para a avaliação da qualidade fisiológica de sementes de soja, cultivar 'IAC 18', peneiras 12 e 13, e cultivar 'IAC 22', peneiras 12, 13 e 14.

\begin{tabular}{|c|c|c|c|c|c|c|c|c|c|c|}
\hline \multicolumn{11}{|c|}{ IAC 18} \\
\hline \multirow[t]{2}{*}{ Peneira } & $\mathrm{M} 1000 \pm \mathrm{S}$ & $\mathrm{U}$ & G & $\mathrm{CV}$ & PCG & $\mathrm{CH}$ & $\mathrm{CR}$ & MSPA & MSR & LK \\
\hline & (g) & \multicolumn{4}{|c|}{$(\%)$} & \multicolumn{2}{|c|}{$(\mathrm{cm})$} & \multicolumn{2}{|c|}{ (g) } & $\left(\mathrm{ppmK}^{+} /\right.$gsem $)$ \\
\hline 12 & $123,34 \pm 0,14$ & 8,5 & $82 a^{*}$ & $49 \mathrm{a}$ & $80 \mathrm{a}$ & $3,312 \mathrm{a}$ & $6,850 \mathrm{a}$ & $0,102 \mathrm{~b}$ & $0,037 \mathrm{a}$ & $269,9 a$ \\
\hline 13 & $146,70 \pm 0,33$ & 8,9 & $90 \mathrm{a}$ & $56 \mathrm{a}$ & $89 \mathrm{a}$ & $4,175 \mathrm{a}$ & $8,338 \mathrm{a}$ & $0,133 \mathrm{a}$ & $0,045 \mathrm{a}$ & $265,4 \mathrm{a}$ \\
\hline \multicolumn{11}{|c|}{ IAC 22} \\
\hline \multirow[t]{2}{*}{ Peneira } & $\mathrm{M} 1000 \pm \mathrm{S}$ & $\mathrm{U}$ & G & $\mathrm{CV}$ & PCG & $\mathrm{CH}$ & $\mathrm{CR}$ & MSPA & MSR & LK \\
\hline & (g) & \multicolumn{4}{|c|}{$(\%)$} & \multicolumn{2}{|c|}{$(\mathrm{cm})$} & \multicolumn{2}{|c|}{ (g) } & $\left(\mathrm{ppmK}^{+} /\right.$gsem $)$ \\
\hline 12 & $120,05 \pm 0,14$ & 8,3 & $91 \mathrm{a}$ & $66 \mathrm{a}$ & $90 \mathrm{a}$ & $3,913 \mathrm{a}$ & $10,137 \mathrm{a}$ & $0,108 \mathrm{a}$ & $0,049 \mathrm{a}$ & $238,1 \mathrm{a}$ \\
\hline 13 & $142,10 \pm 0,22$ & 8,3 & $93 \mathrm{a}$ & $71 \mathrm{a}$ & $91 \mathrm{a}$ & $3,600 \mathrm{a}$ & $10,013 \mathrm{a}$ & $0,103 \mathrm{a}$ & $0,038 \mathrm{a}$ & $290,5 \mathrm{a}$ \\
\hline 14 & $161,52 \pm 0,13$ & 8,4 & $99 \mathrm{a}$ & $71 \mathrm{a}$ & $99 \mathrm{a}$ & $6,650 \mathrm{a}$ & $7,613 \mathrm{a}$ & $0,118 \mathrm{a}$ & $0,048 \mathrm{a}$ & $287,7 \mathrm{a}$ \\
\hline
\end{tabular}

Médias do mesmo cultivar seguidas pela mesma letra, na coluna, não diferem entre si pelo teste de Tukey, a 5\% de probabilidade.

$\mathbf{M 1 0 0 0}=$ massa de mil sementes; $\mathbf{S}=$ desvio padrão; $\mathbf{U}=$ grau de umidade; $\mathbf{G}=$ germinação; $\mathbf{C V}=$ classificação de vigor; $\mathbf{P C G}=$ primeira contagem de germinação; $\mathbf{C H}=$ comprimento do hipocótilo; $\mathbf{C R}=$ comprimento de raiz; $\mathbf{M S P A}=$ massa seca da parte aérea; $\mathbf{M S R}=$ massa seca da raiz; $\mathbf{L K}=$ lixiviação de potássio

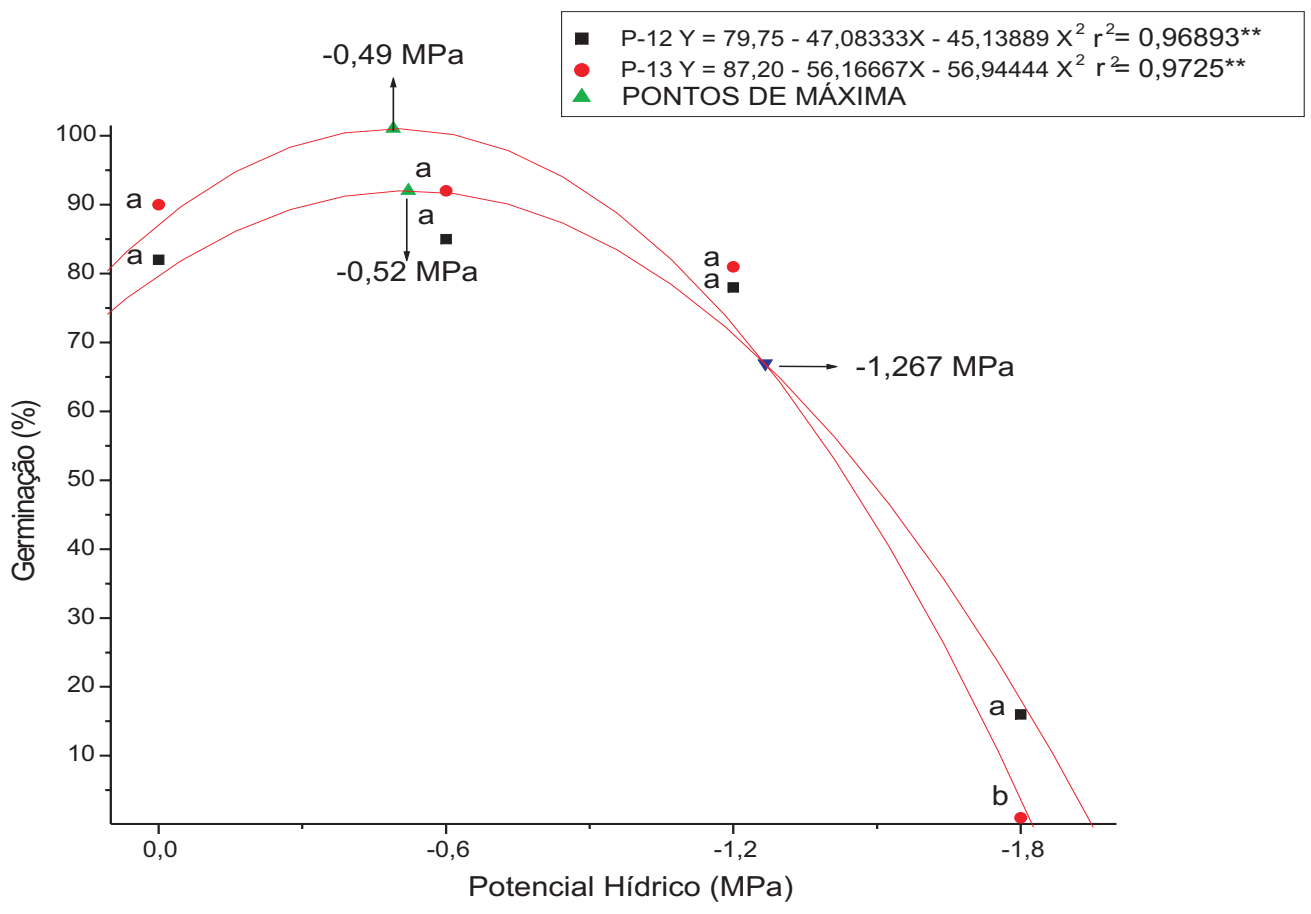

FIGURA 1. Germinação de sementes de soja, cultivar 'IAC-18', para as peneiras 12 e 13, submetidas a deficiência hídrica induzida por diferentes concentrações de manitol. (Presidente Prudente - SP, 2002). Dentro de cada potencial hídrico, médias seguidas por mesma letra não diferem entre si pelo teste de Tukey, a $5 \%$ de probabilidade.

-1,267MPa, o resultado de germinação seria igual para os dois tamanhos de sementes, ou seja, 67\%. Em potenciais hídricos menores que $-1,267 \mathrm{MPa}$, as sementes de menor tamanho apresentaram-se vantajosas, pois germinaram mais que as de maior tamanho. Na máxima deficiência hídrica estudada, -1,8MPa, as sementes maiores não germinaram enquanto as sementes menores produziram $18 \%$ de germinação, tendo apresentado diferença significativa entre os tratamentos $(\mathrm{P}<0,05)$.

Para a variável primeira contagem de germinação ocorreu redução linear no vigor das sementes conforme o potencial hídrico diminuía, para o cultivar 'IAC-18' (Figura 2a), 
considerando a média dos tratamentos de tamanho das sementes, uma vez que não houve diferença significativa $(\mathrm{P}>0,05)$ entre as sementes classificadas nas peneiras $12 \mathrm{e}$ 13, nos diferentes níveis de potencial hídrico. Na avaliação de classificação do vigor das plântulas (Figura 2b), as sementes de maior tamanho (peneira 13) não apresentaram diferença significativa com as sementes menores (peneira 12) até o nível de potencial hídrico de -1,2MPa, invertendo-se esta situação no tratamento $-1,8 \mathrm{MPa}$.

Nos resultados de avaliação do comprimento e massa seca das plântulas, apenas a determinação de comprimento de hipocótilo apresentou diferença significativa $(\mathrm{P}<0,05)$ entre os tamanhos de sementes (Figura 3a). Nas outras determinações, os tamanhos de sementes, nos diferentes níveis de manitol, não foram significativos, sendo apresentados os resultados médios das peneiras 12 e 13 (Figuras 3b, 3c e 3d). Com a diminuição do potencial hídrico ocorreu redução linear de todas as avaliações. Analisando-se o potencial de $-0,6 \mathrm{MPa}$ observa-se que estas características (Figura 3) foram mais afetadas que a germinação das sementes (Figura 1), indicando maior sensibilidade ao estresse hídrico. Na maior parte dos trabalhos revisados, os autores também constataram que a germinação é uma característica menos sensível para indicar diferenças na qualidade das sementes submetidas a condição de deficiência hídrica (Cazetta et al., 1995; Braccini et al.,
1998; Braga et al., 1999; Aguiar et al., 2001; Moraes \& Menezes, 2003).

As sementes de soja do cultivar 'IAC-22' não apresentaram diferenças entre os tamanhos quanto a porcentagem de germinação, para os níveis de potencial hídrico de -0,6 e -1,2MPa. Os resultados de germinação, obtidos em função dos diferentes potenciais hídricos, nos três tamanhos de sementes, permitiram o ajuste de equações quadráticas (Figura 4). Foi possível o estabelecimento dos potenciais hídricos de -0,46,-0,51 e -0,514MPa como pontos de obtenção de máxima germinação, respectivamente, para as sementes classificadas nas peneiras 14, 13 e 12. Do mesmo modo, verificou-se que no potencial de $-1,04 \mathrm{MPa}$ o resultado da porcentagem de germinação foi igual para os três tamanhos de sementes, ou seja, 90\% de germinação. Em potenciais hídricos inferiores a $-1,04 \mathrm{MPa}$, as sementes de menor tamanho (peneira 12) são mais vantajosas para serem utilizadas comercialmente, pois apresentaram maior porcentagem de germinação do que as maiores.

Para as variáveis primeira contagem de germinação e classificação do vigor das plântulas ocorreu diminuição do vigor com a redução no potencial hídrico (Figuras 5a e 5b). Não houve diferença significativa $(\mathrm{P}>0,05)$ entre os tamanhos de sementes do cultivar "IAC-22" para a variável primeira contagem de germinação, enquanto que para variável

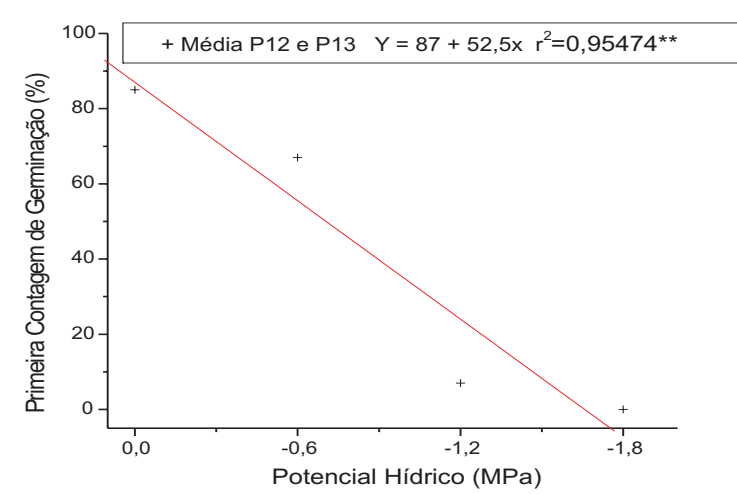

(a)

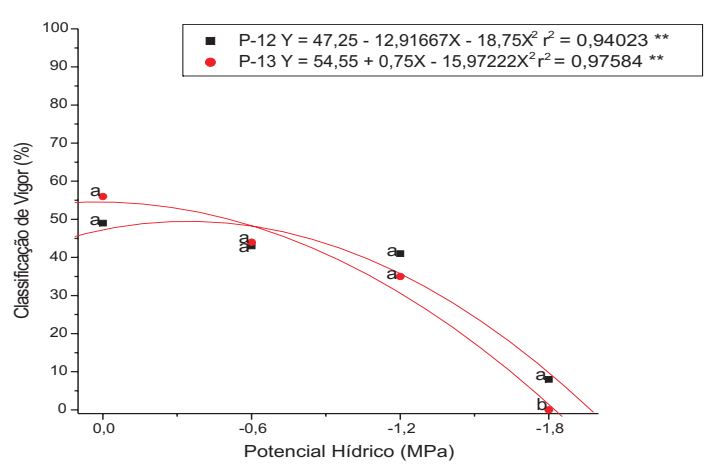

(b)

FIGURA 2. Primeira contagem de germinação (a) e classificação do vigor das plântulas (b) de sementes de soja, cultivar 'IAC-18', para as peneiras 12 e 13, submetidas a deficiência hídrica induzida por diferentes concentrações de manitol. (Presidente Prudente -SP, 2002). Dentro de cada potencial hídrico, médias seguidas por mesma letra não diferem entre si pelo teste de Tukey, a 5\% de probabilidade. 


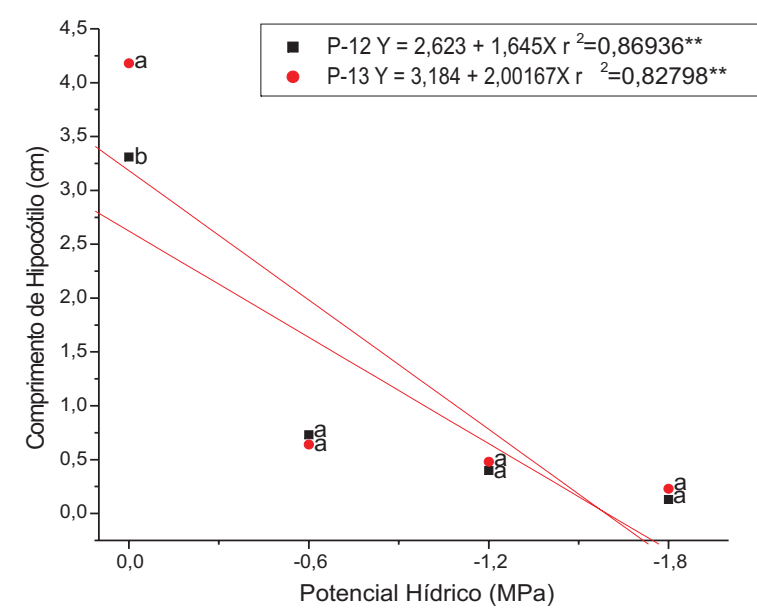

(a)

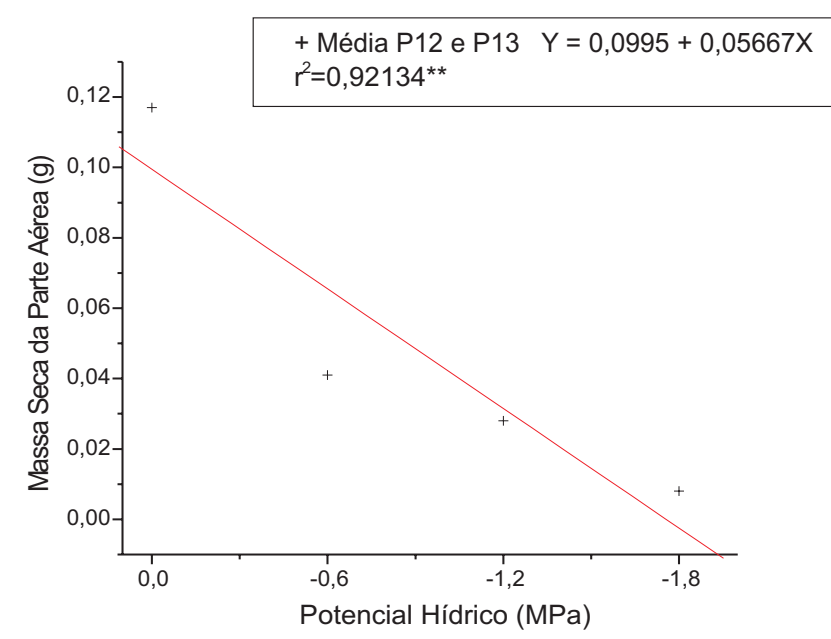

(c)

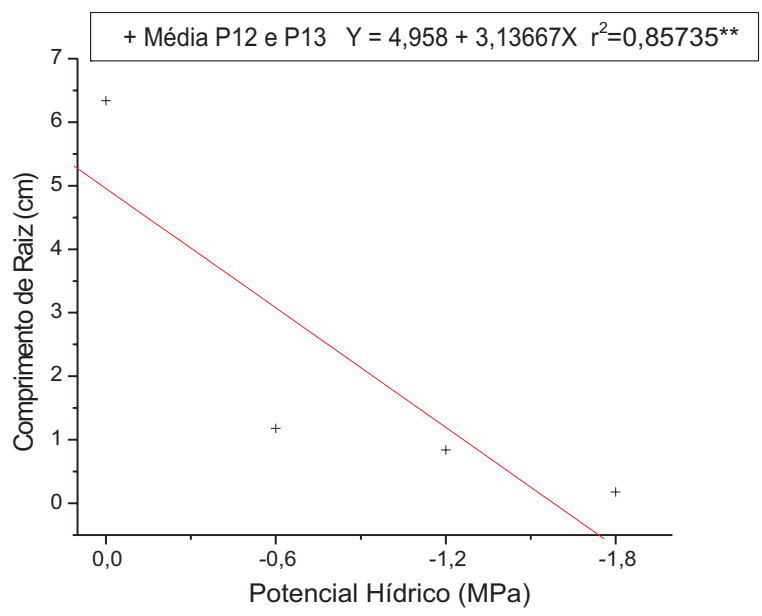

(b)

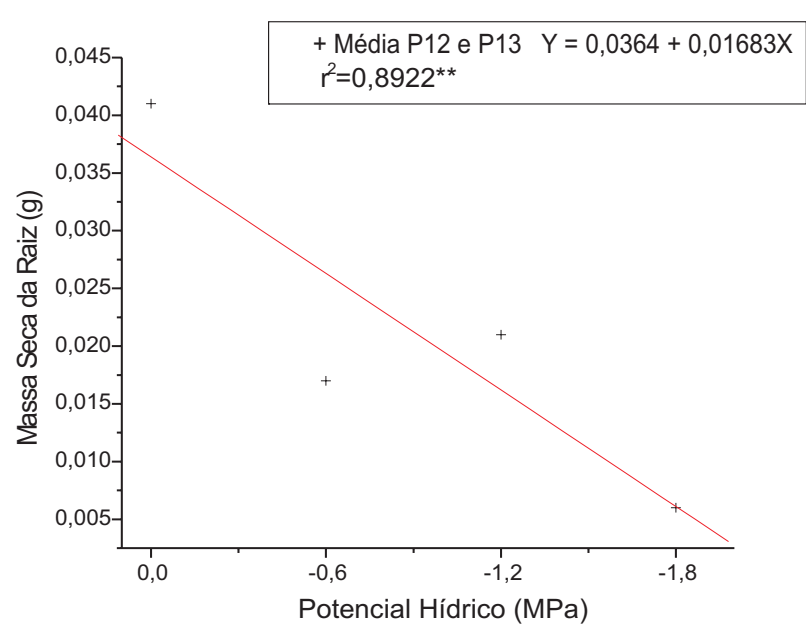

(d)

FIGURA 3. Comprimento do hipocótilo (a) e da raiz (b) e massa seca da parte aérea (c) e da raiz (d) de plântulas de soja, cultivar 'IAC18', para as peneiras 12 e 13, submetidas a deficiência hídrica induzida por diferentes concentrações de manitol. (Presidente Prudente-SP, 2002). Dentro de cada potencial hídrico, médias seguidas por mesma letra não diferem entre si pelo teste de Tukey, a $5 \%$ de probabilidade.

classificação do vigor das plântulas foi observada diferença entre os tratamentos apenas no nível de potencial hídrico de $1,8 \mathrm{MPa}$.

$\mathrm{Na}$ avaliação do desempenho das plântulas, por meio do comprimento e da massa seca do cultivar 'IAC-22', apenas a determinação do comprimento de raiz apresentou diferença significativa $(\mathrm{P}<0,05)$ na classificação das sementes por tamanho (Figura $6 b$ ). Nas demais avaliações, os tamanhos de sementes não foram significativos nos diferentes níveis de manitol, sendo apresentados apenas os resultados das médias de classificação nas três peneiras (Figura 6a, 6c e 6d). Com a diminuição do potencial hídrico ocorreu redução linear para todas as avaliações.

Em relação ao tamanho das sementes, alguns trabalhos tem indicado que, em condições favoráveis de umidade, sementes maiores são mais vigorosas e produzem plântulas 


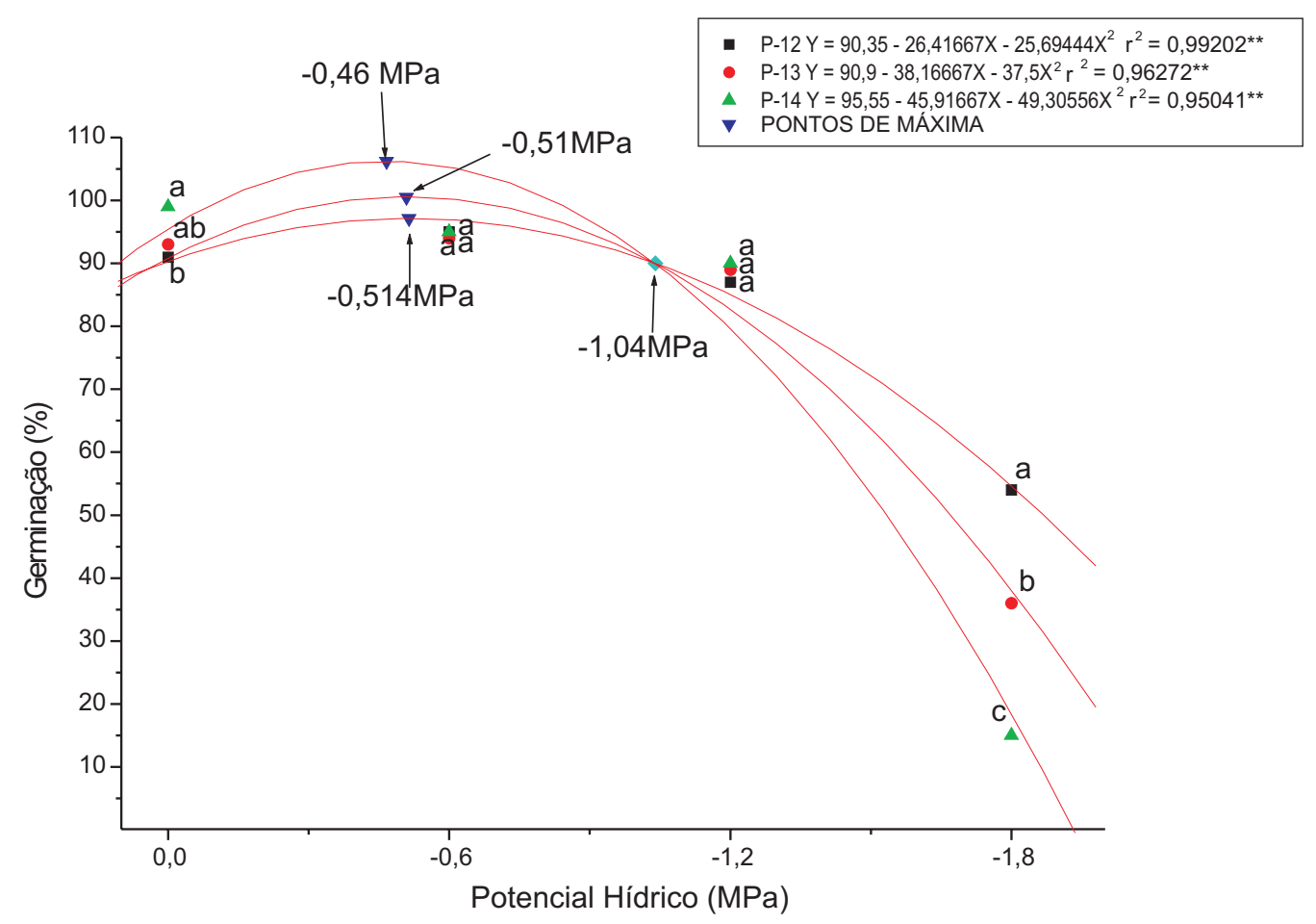

FIGURA 4. Germinação de sementes de soja, cultivar 'IAC-22', para as peneiras 12, 13 e 14, submetidas a deficiência hídrica induzida por diferentes concentrações de manitol. (Presidente Prudente - SP, 2002). Dentro de cada potencial hídrico, médias seguidas por mesma letra não diferem entre si pelo teste de Tukey, a $5 \%$ de probabilidade.

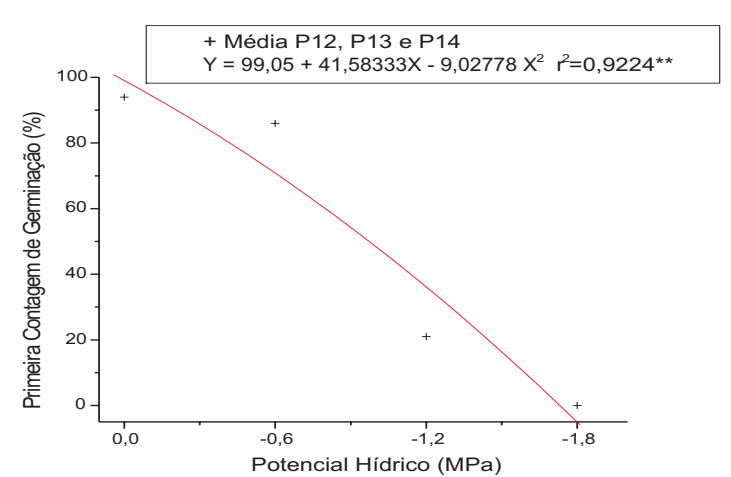

(a)

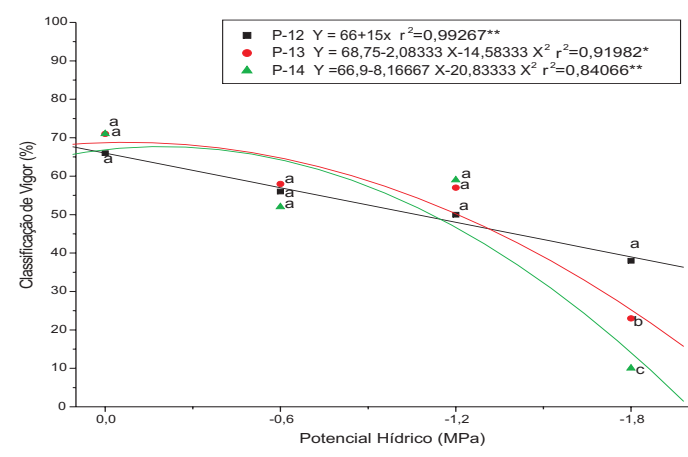

(b)

FIGURA 5. Primeira contagem de germinação (a) e classificação do vigor das plântulas (b) de sementes de soja, cultivar 'IAC-22', para as peneiras 12, 13 e 14, submetidas a deficiência hídrica induzida por diferentes concentrações de manitol. (Presidente Prudente-SP, 2002). Dentro de cada potencial hídrico, médias seguidas por mesma letra não diferem entre si pelo teste de Tukey, a $5 \%$ de probabilidade.

com maior massa (Cazetta et al., 1995). No entanto, os resultados obtidos no presente trabalho não indicaram essa relação, pois, na maioria dos testes de vigor utilizados, mesmo na ausência de restrição hídrica, as sementes menores não diferiram das maiores (Tabela 1 e Figura 1). Foram observadas diferenças significativas para as sementes maiores apenas na determinação do comprimento de hipocótilo, na condição de estresse hídrico, para o cultivar "IAC-18" (Figura 3a), e para 


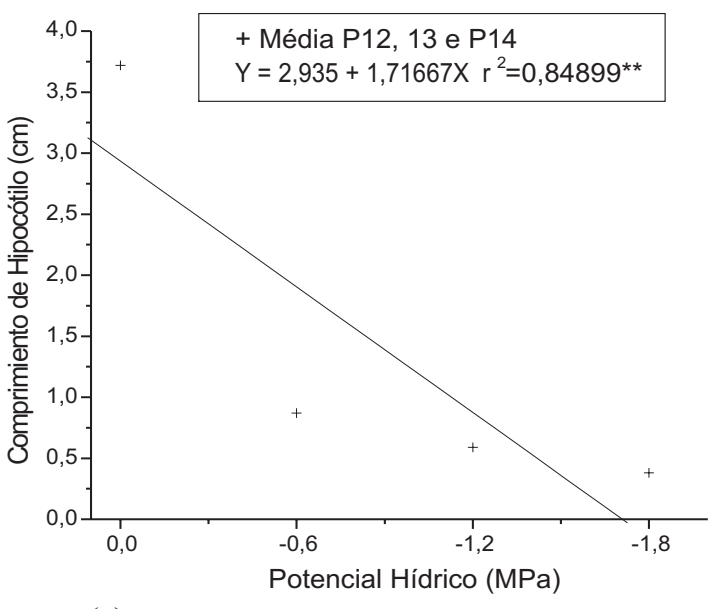

(a)

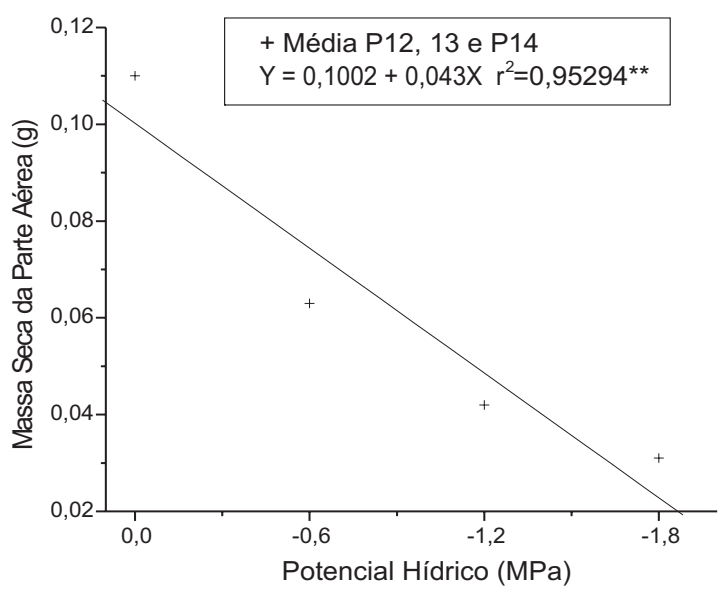

(c)

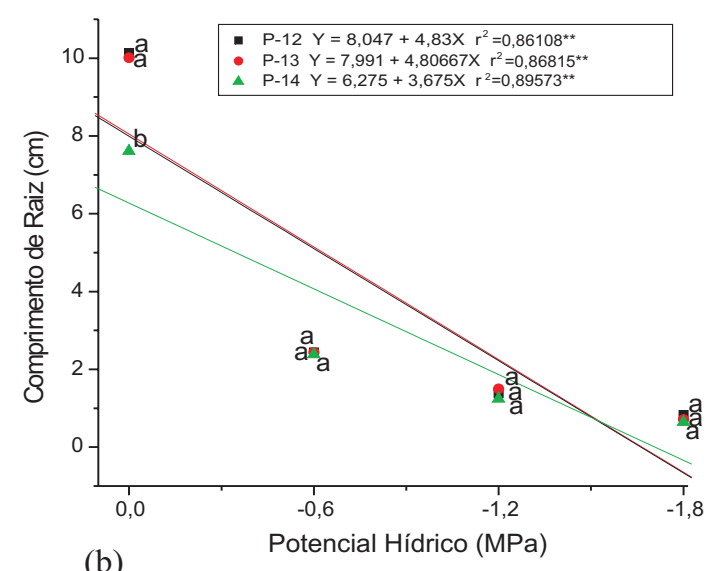

(b)

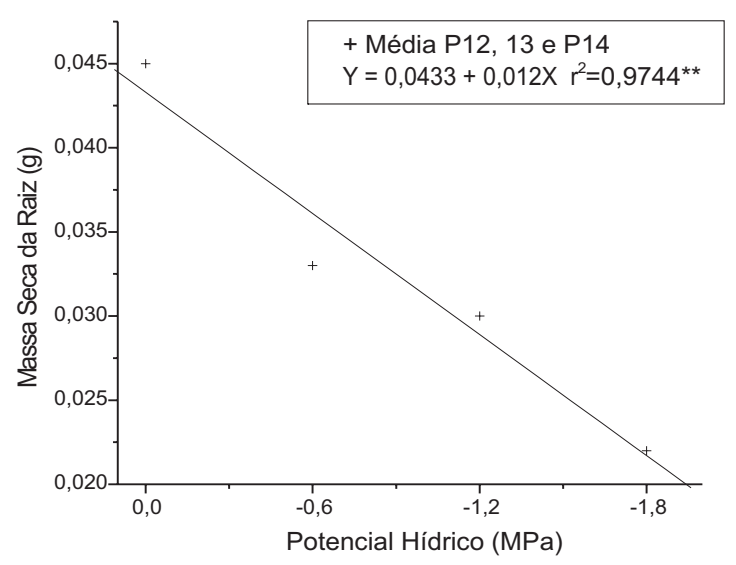

(d)

FIGURA 6. Comprimento do hipocótilo (a) e da raiz (b) e massa seca da parte aérea (c) e da raiz (d) de plântulas de soja, cultivar 'IAC22', para as peneiras 12,13 e 14, submetidas a deficiência hídrica induzida por diferentes concentrações de manitol. (Presidente Prudente - SP, 2002). Dentro de cada potencial hídrico, médias seguidas por mesma letra não diferem entre si pelo teste de Tukey, a $5 \%$ de probabilidade.

avaliação da germinação, da classificação do vigor e do comprimento de raiz, sob restrição hídrica, para o cultivar 'IAC-22' (Figuras 4, 5b e 6b). Em trabalho visando avaliar o efeito da absorção de água no potencial fisiológico de sementes de soja de diferentes tamanhos, Beckert et al. (2000), concluíram que uma diferença de $0,79 \mathrm{~mm}$ no tamanho das sementes, para mais ou menos, em relação às de tamanho médio $(5,55 \mathrm{~mm})$ reduziu a qualidades daquelas.

\section{CONCLUSÕES}

A germinação de sementes de soja é favorecida quando submetida a uma restrição hídrica de $-0,46$ a $-0,52 \mathrm{MPa}$;

Sementes menores tendem a apresentar maior porcentagem de germinação em relação a sementes maiores, em situações de deficiência hídrica acima de -1,0MPa;

O desenvolvimento das plântulas é mais afetado que a germinação com a diminuição do potencial hídrico. 
A qualidade fisiológica não é afetada pelo tamanho das sementes;

\section{REFERÊNCIAS}

AGUIAR, R.H.; FANTINATTI, J.B.; GROTH, D.; USBERTI, R. Qualidade física, fisiológica e sanitária de sementes de girassol de diferentes tamanhos. Revista Brasileira de Sementes, Brasília, v.23, n.1, p.134-139, 2001.

BECKERT, O.P.; MIGUEL, M.H.; MARCOS FILHO, J. Absorção de água e potencial fisiológico em sementes de soja de diferentes tamanhos. Scientia Agrícola, Piracicaba, v.57, n.3, p. 671-675, 2000.

BRACCINI, A.L.; REIS, M.S.; SEDIYAMA, C.S.; SEDIYAMA, T.; ROCHA, V.S. Influência do potencial hídrico induzido por polietilenoglicol na qualidade fisiológica de sementes de soja. Pesquisa Agropecuária Brasileira, Brasília, v.33, n.9, p.1451-1459, 1998.

BRAGA, L.F.; SOUSA, M.P.; BRAGA, J.F.; SÁ, M.E. Efeito da disponibilidade hídrica do substrato na qualidade fisiológica de sementes de feijão. Revista Brasileira de Sementes, Brasília, v.21, n.2, p.95-102, 1999.

BRASIL. Ministério da Agricultura e Reforma Agrária. Regras para análise de sementes. Brasília: SNDA/DNDV/CLAV, 1992. $365 \mathrm{p}$.

CALERO, E.; WEST, S.H.; HINSON, K. Water absorption of soybean associate causal factors. Crop Sciense, Madison, v.21, p.926-933, 1981.

CAZETTA, J.O.; SADER, R.; IKEDA, M. Efeito do tamanho no desempenho germinativo de sementes de feijoeiro (Phaseolus vulgaris L.). Científica, São Paulo, v.23, n.1, p.65-71, 1995.

FERREIRA, M.G.R.; TORRES, S.B. Influência do tamanho das sementes na germinação e no vigor de plântulas de Acacia senegal (L.) Willd. Revista Brasileira de Sementes, Brasília, v. 22, n.1, p.271-275, 2000.

GODOY, I.J.; RAZERA, L.F.; TICELLI, M; MARTINS, A.L.M.; PEREIRA, J.C.V.N.A. Efeito do tamanho e origem das sementes de amendoim, cultivar Tatu, na produtividade e características das sementes produzidas. Revista Brasileira de Sementes, Brasília, v.18, n.1, p.77-82, 1996.

LIMA, A.M.M.P.; CARMONA, R. Influência do tamanho da semente no desempenho produtivo da soja. Revista Brasileira de Sementes, Brasília, v.21, n.1, p.157-163, 1999.

MARTINELLI-SENEME, A.; MARTINS, C.C.; NAKAGAWA, J.
Germinação de milho cv. AL-34 em função do tamanho da semente e do potencial hídrico do substrato. Revista Brasileira de Sementes, Brasília, v.22, n.2, p.131-138, 2000.

MARTINELLI-SENEME, A.; ZANOTTO, M.D.; NAKAGAWA, J. Efeito da forma e do tamanho da semente na produtividade do milho cultivar AL-34. Revista Brasileira de Sementes, Brasília, v.23; n.1, p.40-47, 2001.

MORAES, G.A.F.; MENEZES, N. L. Desempenho de sementes de soja sob condições diferentes de potencial osmótico. Ciência Rural, Santa Maria, v. 33, n. 2, p. 219-226, 2003.

NAKAGAWA, J. Testes de vigor baseados no desempenho das plântulas. In: KRZYZANOWSKI, F.C., VIEIRA, R.D., FRANÇA NETO, J.B.Vigor de sementes: conceitos e testes. Londrina: ABRATES, 1999.218p.

NOGUEIRA, M.C.S. Curso de estatística experimental aplicada a experimentação agronômica. Piracicaba: ESALQ, 1991. 168p.

PESKE, S.T.; DELOUCHE, J.C. Semeadura de soja em condições de baixa umidade do solo. Pesquisa Agropecuária Brasileira, Brasília, v. 20, n. 1, p. 69-85, 1985.

PIANA, Z. Influência do tamanho da semente de soja (Glycine $\operatorname{Max}$ (L.) Merrill) e nível de umidade do solo na germinação e no vigor. 1980. 95f. Dissertação (Mestrado_em Ciência e Tecnologia de Sementes) - Faculdade de Agronomia Eliseu Maciel, Universidade Federal de Pelotas, Pelotas, 1980.

PIANA, Z.; SILVA, W.R. Respostas de sementes de milho com diferentes níveis de vigor à disponibilidade hídrica. Pesquisa Agropecuária Brasileira, Brasília, v.33, n.9, p.1525-1531, 1998.

ROSSETO, C.A.V.; NOVEMBRE, A.D. L.C.; MARCOS FILHO, J.; SILVA, W.R.; NAKAGAWA, J. Efeito da disponibilidade hídrica do substrato, da qualidade fisiológica e do teor de água inicial das sementes de soja no processo de germinação. Scientia Agrícola, Piracicaba, v.54, n.1 e 2, p.97-105, 1997.

SÁ, M.E. Relações entre qualidade fisiológica, disponibilidade hídrica e desempenho de sementes de soja (Glycine max (L.) Merrill). 1987. 147f. Tese (Doutorado em Fitotecnia) - Escola Superior de Agricultura Luiz de Queiroz, Universidade de São Paulo, Piracicaba, 1987.

SOUZA, F.H.D. Características físicas das sementes de Calopogonium mucunoides Desv. associadas à qualidade fisiológica e ao padrão de absorção de água: I. Tamanho. Revista Brasileira de Sementes, Brasília, v.18, n.1, p.33-40, 1996.

ZONTA, E.P.; MACHADO, A.D.; SILVEIRA Jr., P. Sistemas de análise estatística para microcomputadores - SANEST. Pelotas: UFPel, 1984. (Registro SEI nº6606-0, Categoria AO).

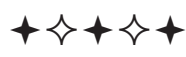

